\title{
The Development of a Concrete Block Containing PET Plastic Bottle Flakes
}

\author{
Tanut Waroonkun ${ }^{1}$, Tanapong Puangpinyo ${ }^{1} \&$ Yuttana Tongtuam $^{1}$ \\ ${ }^{1}$ Building Technology Innovation and Management Center, Faculty of Architecture, Chiang Mai University, \\ Thailand \\ Correspondence: Tanut Waroonkun, Building Technology Innovation and Management Center, Faculty of \\ Architecture, Chiang Mai University, Chiang Mai, 50200, Thailand. Tel: 66-53-94-2806. E-mail: \\ tanut.w@cmu.ac.th
}

Received: October 7, 2017

Accepted: October 19, $2017 \quad$ Online Published: November 29, 2017

doi:10.5539/jsd.v10n6p186

URL: https://doi.org/10.5539/jsd.v10n6p186

\begin{abstract}
Plastic waste is increasing continuously, especially in the form of throw away packaging such as drinking water bottles, designed to be convenient, inexpensive, and accessible. Plastic disposal, however, is difficult and has a lower recyclability rate than other types of materials such as glass and paper. This study presents a method of reducing the amount of plastic waste by recycling plastic containers in architectural work. Non-load-bearing concrete blocks for safe and efficient use can be manufactured using plastic flakes as an alternative material aggregate. This study developed such block sand tested them for compressive strength integrating four major factors:(1) the cement to aggregate ratio, (2) the water to cement ratio, (3) the size of plastic flakes used and (4) the proportion of plastic flake that replaced sand. The findings revealed that using a ratio of $1: 3$ cement to aggregate, where the aggregate mix comprised of $20 \%$ small and medium sized (combined at 1:1) plastic flakes plus $80 \%$ sand and a water to cement ratio of 0.5 , provided the optimal compressive strength to form a concrete block that can be used to construct a non-load bearing wall.
\end{abstract}

Keywords: concrete block, alternative material, plastic water bottle, compressive strength, mixing ratio

\section{Introduction}

The development of technology has brought many comforts to the ever increasing world population. Such progress, however, has also increased the demand for energy and, as a consequence, created massive environmental damage. A further danger to the environment is the growth of the consumer society, typified by convenience and disposability. The popularity of the plastic water bottle illustrates the escalating problems of consumption and waste. Out of the total waste produced (Pollution Control Department, 2002) $15-20 \%$ is synthetic materials, including plastics, and $60 \%$ solid waste. However, only $30 \%$ of plastic can be disposed of by recycling, or by melting, incinerating and processing methods which emit environmentally destructive gasses into the atmosphere. Landfill is a popular method of waste disposal but this method comes at a high environmental cost. Landfill produces toxins that are released into the atmosphere or leach through the soil to contaminate ground and river water supplies and eventually the destruction of marine ecosystems (Jambeck et al., 2015). In addition, composting is not possible because the plastic used in water containers can take up to 700 years to decompose (Rochman et al., 2016). As the demand for plastics increases, especially in the form of packaging, the petro-chemical industry continues with its contribution towards the greenhouse effect which is considered a major attribute to global warming (Cox et al., 2000). The properties of plastic bottles made from \# 1 PET (Polyethylene Terephthalate) have been studied extensively (Asdrubali et al., 2015). PET is a lightweight polymer, with a relatively low density, at about $15-60 \mathrm{~kg} / \mathrm{m}^{3}$. If PET plastic bottle flakes are mixed with, or used to replace, the aggregates of general construction materials, such as mixing with concrete or forming bricks, it can make the building material lower in weight and density. Thus, producing a light weight but strong material that can be used in general construction such as building a wall.

Research related to the use of plastic in building applications is principally about its combination with cement. Most research has focused on building structures, such as slabs, piles and beams, all of which must be able to bear compression well. The addition of plastic flakes is intended to supplement the compressive strength of the block, and act as a replacement to the original mix. Comparisons were made in each study to establish the 
amounts and ratios of the various components used in forming a cement block. The information gathered was used to determine optimal mixing ratios and plastic particle sizes. In addition the compression values of the blocks, formed from each mix, were analysed for their suitability of use in constructing non-load-bearing walls.

Overall, each piece of research mentioned: 1) The type of plastic used. 2) The concrete and aggregate constituents. 3) The defining variables of the mix, such as ratios and quantities. 4) The testing of the mechanical properties of the blocks regarding strength and compression. Marzouk et al. (2007) filtered plastic flakes into three sizes: (1) Type A, (2) Type C, and (3) Type D at 5, 2 and $1 \mathrm{~mm}$ respectively. Then, sand-aggregate was replaced with plastic flake aggregate by $2,5,10,15,20,30,50,70$, and100 percentage points each test. The cement to aggregate ratio (C/A) was 2: 2.8 , and the water to cement ratio (W/C) was 0.5 . The results showed that at $20 \%$ replacement of Type A $(5 \mathrm{~mm}$.), the compressive strength was $58 \mathrm{MPa}$ which was better than no sand-aggregate replacement ( $0 \%$ PET) at $56.2 \mathrm{MPa}$. At 100\% PET replacement, strength was significantly reduced to $19.8 \mathrm{MPa}$ while Types $\mathrm{C}$ and $\mathrm{D}$ had less compressive strength than those with no replacement at all. With ten percent PET the blocks had the compressive strength of 55 and $53 \mathrm{MPa}$.

Rahmani et al. (2013) used ground and filtered plastic, (ranging from $7 \mathrm{~mm}$ to $150 \mu \mathrm{m}$, with the largest percent on sieve at approximately $2 \mathrm{~mm}$ ) to form concrete blocks, and then compared the compressive strengths of the blocks by replacing sand at $0,5,10$, and $15 \%$, applying a [cement : gravel :sand ] ratio of 1:2:1.5 and water to cement ratio $(\mathrm{W} / \mathrm{C})=0.422$ and $(\mathrm{W} / \mathrm{C})=0.54$. The results showed that $5 \%$ replacement was the best compression ratio increasing from the reference samples of $8.86 \%(\mathrm{~W} / \mathrm{C}=0.42)$ and $11.97 \%(\mathrm{~W} / \mathrm{C}=0.54)$. Then the compressive strength gradually decreased to the replacement of $15 \%$.

Albano et al (2009) compared block strength using different sizes of filtered plastic flakes: small (S) $2.6 \mathrm{~mm}$, large (L) $11.4 \mathrm{~mm}$, mixed (A) 50/50 small and large. Aggregates were replaced with plastic at 0,10 and $20 \%$, using a water to cement ratio (W/C) of 0.5 and 0.6. The results showed that blocks utilising a 50/50 (A) mix and small (S) plastic flakes with an aggregate replacement of $10 \%(\mathrm{~W} / \mathrm{C}=0.5)$ could bear similar compressive strengths at 23.2 and 23.1 MPa, while the large size (L) had a compressive strength of $21.5 \mathrm{MPa}$ which was better at a replacement of $20 \%$. Using a w/c ratio of 0.6 , the blocks could bear less compressive strength compared to the aggregate replacement of $10 \%$ and $20 \%$ using the same flake size in both tests.

Frigione (2010) ground PET to sizes between $0.1-5 \mathrm{~mm}$ before filtering the PET to the dimensions of sand grains. Then sand was replaced at 5\% using a cement-aggregate ratio of 1:7 and 1:4.8, and a water-to-cement ratio of 0.45 and 0.55 . The results showed that the ratio of $1: 4.8(\mathrm{~W} / \mathrm{C}=0.45)$ had the best compressive strength at $69.7 \mathrm{MPa}$, followed by the $1: 7$ ratio $(\mathrm{W} / \mathrm{C}=0.45)$ at 67.5 . The ratio of water to cement of 0.45 had higher compressive strength than at 0.55 .

Rahman et al. (2013) ground and filtered plastic flakes into two sizes: 1) $2 \mathrm{~mm},-60 \%$ of all plastic flakes, 2) 3 $\mathrm{mm},-90 \%$ of all plastic flakes. The two sizes were compared replacing sand at $0,3,7,20$, and $30 \%$ with (C/A) ratio of $1: 3$, and water to cement ratio of 0.45 . The results showed that the replacement of $3 \%$ would drastically reduce the compressive strength of the block from $19.5 \mathrm{MPa}$ to $8 \mathrm{MPa}$ when compared to the reference concrete $(0 \%$ PET). However, replacement levels did not widely vary, extending between $6-8 \mathrm{MPa}$ in the range of 20 and $30 \%$ replacement, and could bear a compressive strength of approximately $6 \mathrm{MPa}$. This indicated that the shape and size of the plastic flakes, that do not exceed $3 \mathrm{~mm}$, might affect the blocks strength.

Shalaby et al. (2013) ground and filtered plastic flakes to the fineness modulus of 5.73. Then the blocks were compared for compressive strength replacing $0,10,20,30$, and $50 \%$ of the sand with plastic and using a 1:3 (C/A) ratio, and water to cement ratio of 0.46 . It was found that at $10 \%$ replacement, the blocks could bear the highest compressive strength, at $30.4 \mathrm{MPa}$, followed by the reference concrete $(0 \%$ PET). The strength value gradually reduced when replacing sand with PET at 20, 30, 50\% to $18.27,9.93,2.67 \mathrm{MPa}$ respectively.

Akçaözoğlu et al (2013) formed blocks using plastic flakes ranging from $0.5 \mathrm{~mm}$ to $4 \mathrm{~mm}$ with most flakes being $2 \mathrm{~mm}$ or $67 \%$ of the total. The blocks were compared for strength by replacing the aggregates at $0,30,40,50$, and $60 \%$ with $\mathrm{C} / \mathrm{A}$ at $1: 3$, and water to cement ratio of 0.50 . The results showed that at $30 \%$ replacement, the compressive strength was $25.3 \mathrm{MPa}$, a reduction of $40 \%$ from the reference concrete ( $0 \%$ PET), and would decrease by a further $10 \%$ after adding plastic flakes at each of the replacement proportions. At $60 \%$ of plastic addition, the block had a compressive strength of $9.5 \mathrm{MPa}$. 
Table 1. Summary of research related to plastic building materials

\begin{tabular}{|c|c|c|c|}
\hline & & Comparison & \\
\hline Researcher & Size & Replacement (\%) & Ratio \\
\hline $\begin{array}{l}\text { Mazouk et } \\
\text { al.,2007 }\end{array}$ & $\begin{array}{l}\text { Plastic flakes filtered into } \\
\text { three sizes: (1) Type A, } \\
\text { 5mm(2) Type C, } 2 \mathrm{~mm}(3) \\
\text { Type D } 1 \mathrm{~mm}\end{array}$ & $\begin{array}{l}\text { Compressive strengths of blocks } \\
\text { compared by replacing sand with } \\
\text { plastic flake aggregate at } 2,5, \\
10,15,20,30,50,70 \text {, and } 100 \%\end{array}$ & $\begin{array}{c}\text { Cement to aggregate ratio } \\
\text { (C/A) was } 2: 2.8 \text {, and water } \\
\text { to cement ratio }(\mathrm{W} / \mathrm{C}) \text { was } \\
0.5\end{array}$ \\
\hline $\begin{array}{l}\text { Rahmani et } \\
\text { al., } 2013\end{array}$ & $\begin{array}{l}\text { Plastic flake filtered from } 7 \\
\mathrm{~mm} \text { to } 150 \mu \mathrm{m}, \text { with the } \\
\text { largest percent filtered to } \\
\text { approximately } 2 \mathrm{~mm} .\end{array}$ & $\begin{array}{c}\text { Compressive strengths of blocks } \\
\text { compared by replacing sand at } 0 \text {, } \\
5,10 \text {, and } 15 \%\end{array}$ & $\begin{array}{l}\text { Cement : Gravel :Sand } \\
\text { ratio of } 1: 2: 1.5 \text { and water } \\
\text { to cement ratio }(\mathrm{W} / \mathrm{C})= \\
0.42 \text { and }(\mathrm{W} / \mathrm{C})=0.54\end{array}$ \\
\hline $\begin{array}{l}\text { Albano et al., } \\
2009\end{array}$ & $\begin{array}{l}\text { Plastic flakes filtered into: } \\
\text { Small (S) } 2.6 \mathrm{~mm} \text {, Large (L) } \\
11.4 \mathrm{~mm}, \text { mixed with50/50 } \\
\text { small and large }\end{array}$ & $\begin{array}{c}\text { Compressive strengths of blocks } \\
\text { compared by replacing plastic at } \\
0,10 \text { and } 20 \%\end{array}$ & $\begin{array}{c}\text { Water to cement } \\
\operatorname{ratios}(\mathrm{W} / \mathrm{C}) \text { of } 0.5 \text { and } 0.6\end{array}$ \\
\hline $\begin{array}{l}\text { Shalaby et } \\
\text { al., } 2013\end{array}$ & $\begin{array}{l}\text { Plastic flakes filtered to the } \\
\text { fineness modulus of } 5.73 \\
\mathrm{~mm} .\end{array}$ & $\begin{array}{l}\text { Compressive strengths of blocks } \\
\text { compared by replacing } 0,10,20 \text {, } \\
30 \text {, and } 50 \% \text { of the sand with } \\
\text { plastic. }\end{array}$ & $\begin{array}{l}\text { Cement to aggregate ratio } \\
(\mathrm{C} / \mathrm{A}) \text { was } 1: 3 \text {, and water to } \\
\text { cement ratio }(\mathrm{W} / \mathrm{C}) \text { of } 0.46\end{array}$ \\
\hline $\begin{array}{l}\text { Rahman et } \\
\text { al., } 2013\end{array}$ & $\begin{array}{c}\text { Plastic flakes filtered into } \\
\text { two sizes: 1) } 2 \mathrm{~mm} \text { and 2) } 3 \\
\mathrm{~mm} .\end{array}$ & $\begin{array}{c}\text { Compressive strengths of blocks } \\
\text { compared by replacing sand at } 0 \text {, } \\
3,7,20 \text {, and } 30 \%\end{array}$ & $\begin{array}{l}\text { Cement to aggregate ratio } \\
\text { (C/A) was } 1: 3 \text {, and water to } \\
\text { cement ratio }(\mathrm{W} / \mathrm{C}) \text { of } 0.45\end{array}$ \\
\hline $\begin{array}{l}\text { Akçaözoğlu } \\
\text { et al., } 2013\end{array}$ & $\begin{array}{l}\text { Plastic flakes filtered ranging } \\
\text { from } 0.5 \mathrm{~mm} \text { to } 4 \mathrm{~mm} \text {., with } \\
\text { most flakes being } 2 \mathrm{~mm} \text {. or } \\
\quad 67 \% \text { of the total }\end{array}$ & $\begin{array}{c}\text { Compressive strengths of blocks } \\
\text { compared by replacing sand at } 0 \text {, } \\
30,40,50 \text {, and } 60 \%\end{array}$ & $\begin{array}{l}\text { Cement to aggregate ratio } \\
(\mathrm{C} / \mathrm{A}) \text { was } 1: 3 \text {, and water to } \\
\text { cement ratio }(\mathrm{W} / \mathrm{C}) \text { of } 0.5\end{array}$ \\
\hline
\end{tabular}

Research has found that small $(1-4 \mathrm{~mm})$ plastic flakes, produced from water containers, can replace $20-30 \%$ of the aggregates in concrete and still provide sufficient compressive strength. Most studies involved cement and aggregate ratios that would produce concrete with a load bearing compression test result higher than $10 \mathrm{MPa}$. This is higher than the compressive strength requirement for the construction of non-load bearing walls. For example, bricks must bear the compressive strength not lower than $3.5 \mathrm{MPa}$ (TIS 77-2517), with concrete blocks at 2.5 MPa (TIS 58-2533), and lightweight bricks not lower than 2.0 MPa (TIS 1505-2541). Therefore, using plastic flakes as a component of the concrete mix when forming non-load bearing wall blocks, is possible by appropriately adjusting the proportion of plastic flakes used in the aggregate.

This study recognizes the opportunity to use large quantities of plastic waste for architectural purposes by focusing on the development of a wall building material containing plastic bottle waste as a component of the masonry unit or 'brick'. If materials that are not directly designed for building structures are used, such as for a load - bearing walls, the building can be damaged. As such the bricks are designed to appropriately resist the compressive strength of a non-load-bearing concrete block wall. The using of waste plastic bottles is primarily conducted to reduce the burden of waste disposal, in addition to increasing the value of products, from waste materials.

\section{Materials and Methods}

\subsection{Block Development}

The block design integrated:

1) The concrete mix (taking into account the strength, convenience of access and cost). 
2) The mix ratios (including the proportion of binder substances to suit the application).

3) The size and quantity of plastic flakes for optimum effectiveness, and load bearing compressive strength.

\subsection{Type of Concrete Mix}

In the manufacture of concrete blocks, cement is mixed with aggregates, such as sand and quarry dust. However, at this point, sand was chosen to be the main aggregate in the mixture since it could bear the compressive strength well and was cost effective (Ismail, Z.Z. and AL-Hashmi, E.A. 2008). Therefore, the main mix consisted of: (1) Portland cement type 1, (2) sand, and (3) water.

\subsection{Cement to Aggregate Ratio}

The ratio mix varies according to the purpose of concrete application. In the research work, with the addition of plastic flakes for structural work, the ratio of cement to aggregates (C/A) was approximately 1:3. In alternative block production, Oyekan, GL and Kamiyo, OM (2011) added rice husk to replace sand using a 1:6 ratio. Joshua, O. and Lawal, PO (2011) added lateritic soil to replace sand using a 1:6 ratio. Therefore, setting the cement to sand ratio should not be more than the ratio used in most factories, 1:6. If too little cement is used when mixed with plastic flakes, (which are not a common material for building walls), the cement and aggregates will not bond. As a result, in the initial tests, the optimal ratios of cement to aggregates (sand) is set at 1:6,1:5,1:4,1:3, 1: 2, and 1: 1 .

\subsection{Water to Cement Ratio}

In addition to compressive strength tests of blocks that include aggregates of non-typical materials like plastic flakes, tests need to account for the variance in cement to water ratios. It was found that concrete with a water to cement ratio of 0.5 could bear better compression than a 0.6 ratio (Albano et al., 2009). Also Frigione (2010), showed that if a 0.45 ratio is used, the compressive strength was better than a 0.55 ratio. Due to the specificity and size of the plastic flakes when mixed with other aggregates, increasing the proportion of water may improve the ability of the cement to mix with the sand and in turn adherence to the plastic flakes. Moreover, the amount of water will increase the weight and density of the blocks resulting in greater efficiency of heat transfer. As a result, initially, the water to cement ratios were set at 1:2,1:1.4,1:1 or w/ $\mathrm{c}=0.5,0.7$, and 1.0.

\subsection{Optimal Plastic Size}

Plastic bottles are shredded and ground in re-cycling plants before being melted to form plastic resin which is used to make various products. The shredded and ground plastic flakes used to form concrete blocks were the same size as in standard Thai re-cycling programmes which is 0.5 inch or $1.27 \mathrm{~cm}$.

Table 2. Selection of plastic flakes from a plant

\begin{tabular}{cccc}
\hline Size & \% of Selected Mass & Size $(\mathrm{mm})$ & Mesh that cannot filter \\
\hline L1 & $<0.01$ & $9.53-12.70$ & Mesh3/8“ \\
L2 & 43.36 & $4.75-9.53$ & MeshNo.4 \\
L3 & 53.66 & $2.38-4.75$ & Mesh No.8 \\
L4 & 2.98 & $1.19-2.38$ & Mesh No.16 \\
L5 & $<0.01$ & $0.589-1.19$ & Mesh No.30 \\
\hline
\end{tabular}

From table 2, when compared to other aggregates, plastic flakes were relatively large. As a result, they were ground to smaller sizes. 
Table 3. Selection of plastic flakes ground by a plastic grinding machine

\begin{tabular}{cccc}
\hline Size & \% of Selected Mass & Size $(\mathrm{mm})$ & Mesh that cannot filter \\
\hline M1 & 7.54 & $2.38-4.75$ & Mesh No.4 \\
M2 & 72.72 & $1.19-2.38$ & Mesh No.8 \\
M3 & 15.85 & $0.589-1.19$ & Mesh No.16 \\
M4 & 2.39 & $0.297-0.589$ & Mesh No.50 \\
M5 & 1.49 & $0.15-0.297$ & Mesh No.100 \\
\hline
\end{tabular}

From Table 2 and 3, it was found that the three largest volumes of plastic were L2, L3 separated by a sieve and M2 was the size obtained by regrinding. After setting the cement to aggregate ratio, the water to cement ratio, and the size of the plastic flake, the sand aggregate was replaced, in various proportions, by plastic flakes. The blocks were formed and tests conducted to discover what proportion of sand replacement produced optimal compressive strength.
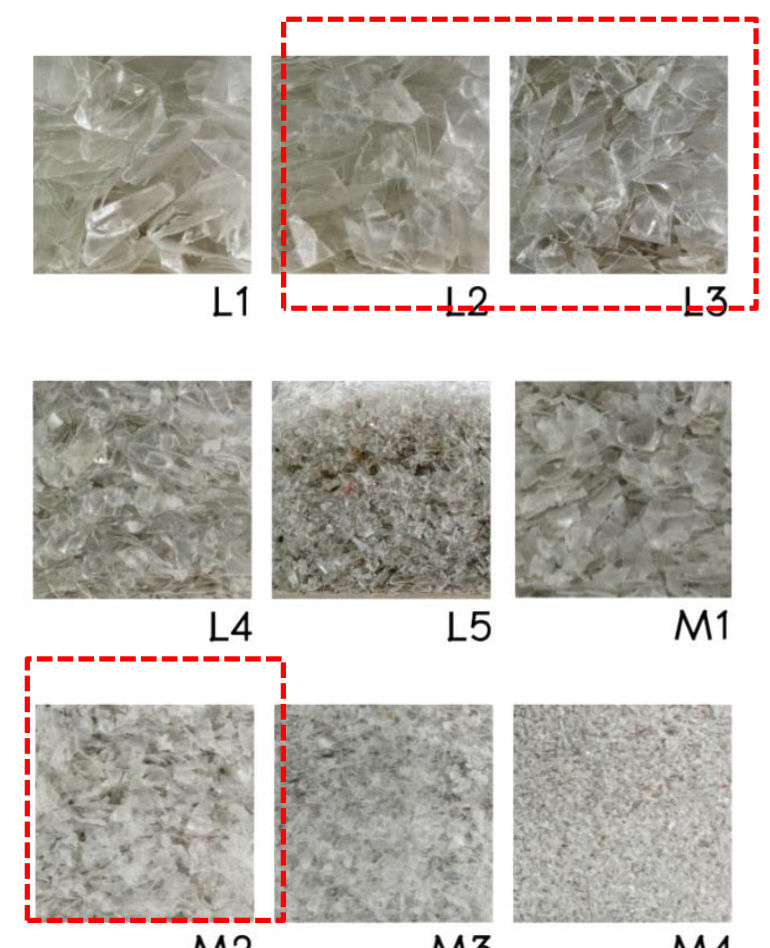

M1

M2

M3
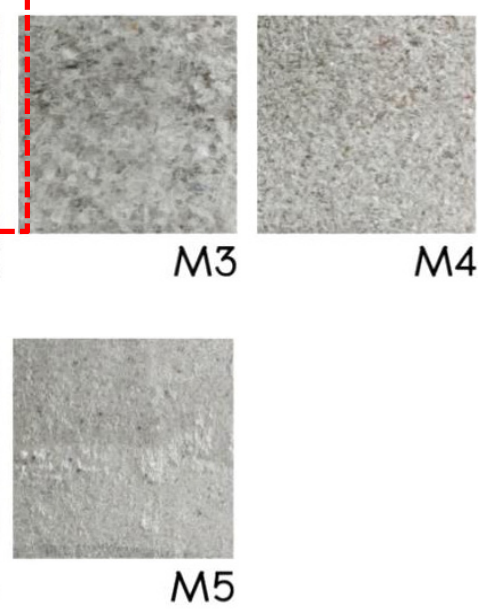

Figure 1. Plastic flakes from re-cycling plant (L) and ground (M)

Three sizes of plastic flakes (L2, L3, M2) were selected, and variables were renamed for easier understanding. 
Table 4. Renaming plastic flakes

\begin{tabular}{ccc}
\hline Plastic flake & Size $(\mathrm{mm})$ & Renamed Variables \\
\hline L2 & $4.75-9.53$ & L (Large) \\
L3 & $2.38-4.75$ & M (Medium) \\
M2 & $1.19-2.38$ & S (Small) \\
\hline
\end{tabular}

In addition to comparing the three basic sizes of plastic flakes, other samples were created by mixing the three sizes. For example, plastic flakes size $\mathrm{L}$ and $\mathrm{M}$ were combined to replace the sand aggregate. Mixing many waste materials of coarse and fine aggregates of various sizes into the concrete mix is not only to find the best way to use the waste materials for maximum efficiency, but also to discover an applicable compressive strength. Therefore, the flake-size evaluation included a single size type, $L, M, S$, and a mixed size types $(L+M),(L+S)$, $(\mathrm{M}+\mathrm{S}),(\mathrm{L}+\mathrm{M}+\mathrm{S})$.

\subsection{Proportion of Plastic Flake Replacement}

In the research, the replacement of aggregates using plastics varied from $0-100 \%$. It was predominantly found that the replacement ratio did not exceed $20 \%$, which is the range where the concrete bears the compression well. Mazouk et al. (2007), Shalaby et al. (2013), Akçaözoğluet al, (2013) set the range of sand replacement at $50-100 \%$ and up to the replacement of $30 \%$, the compressive strength of the blocks reduced gradually. With $30 \%$ or more, the compressive strength was greatly reduced since low density plastic flakes would replace higher density sand. The density of concrete blocks is a factor that affects the compressive strength (Mazouk et al., 2007). In these tests, replacement ranges include $0,5,10,15$, and $20 \%$ of the sand aggregate by weight.

\subsection{Research Design}

From the study of the factors involving the design of a block to build a sample wall, each block's evaluation was divided into: 1) Mixing Ratio 2) Water to Cement Ratio 3) Size of Plastic Flake and Appropriate Proportion of sand Replacement. The first three factors tested discovered the mixing ratio, water to cement ratio, and the appropriate plastic flake size. After that, plastic flakes replaced the aggregate at various proportions.

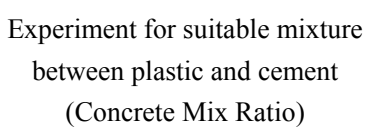

(Concrete Mix Ratio)

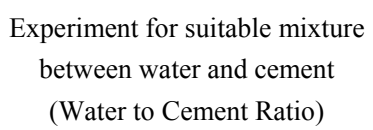

(Water to Cement Ratio)

\author{
Experiment for the selection of the \\ appropriate PET Bottle flake \\ (PET Bottle Flake)
}

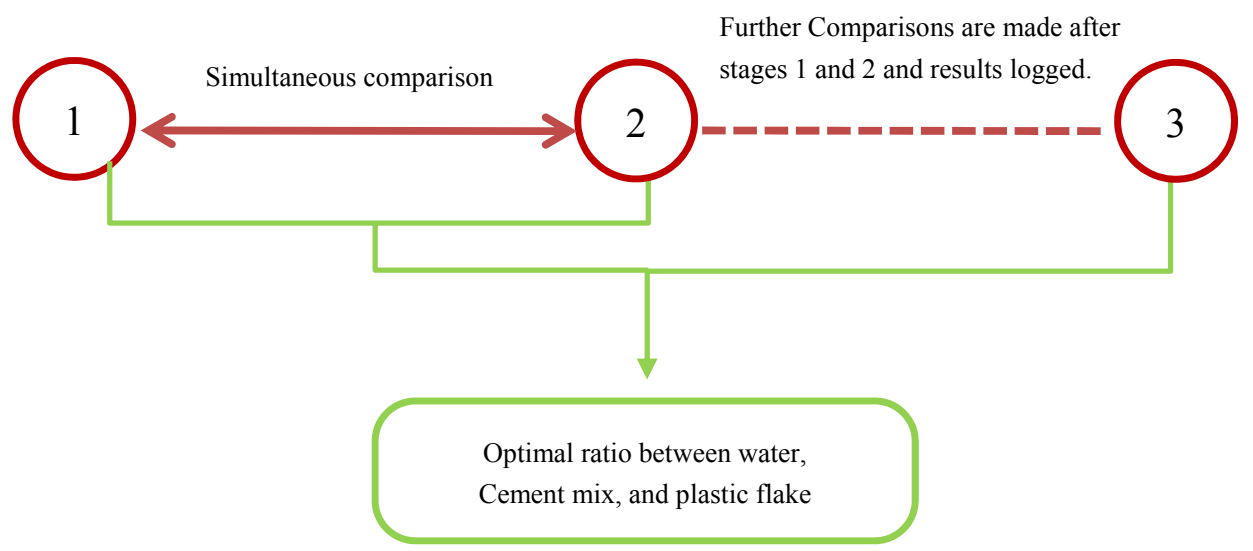

Figure 2 Working process

\subsection{Process of Making a Sample Block}

All ratios of the concrete mix were by weight, and the volume of each block was a standard form of $7 \times 7 \times 7 \mathrm{~cm}$. All samples were cast three times. The cement, sand, and water were mixed well before adding the insoluble plastic flakes which aided the bonding of the cement and aggregates. The concrete was poured into the form, and 
dried in the sun in a well-ventilated area. In the experiment, the mix was left to cure for about 28 days. At the scheduled date, the forms were taken off, and the blocks weighed to calculate density, before being tested for compressive strength.

\subsection{Compression Test}

A universal testing machine was used in each test. Then the compressive strength values obtained from the test were compared. The sample blocks should bear the compressive strength of at least $2 \mathrm{MPa}$, based on the standard specification of lightweight concrete (TIS 1505-2541). After that the sample blocks were placed on a platform and compression increased until they disintegrated. The compressive strength values were calculated by the concrete compression test method (TIS 409-2525) as illustrated in the following equation.

$$
\sigma=\frac{F}{A}
$$

When $\sigma=$ Ultimate strength (MPa or $\mathrm{N} / \mathrm{mm}^{2}$ )

$F=$ Maximum force or weight that the block can with stand $(\mathrm{N})$

$A=$ Cross sectional area of the block $\left(\mathrm{mm}^{2}\right)$

\section{Results and Data Analysis}

\subsection{Block Component Ratios}

Concrete blocks were formed using cement to aggregate ratios of 1:1, 1:2, 1:3, 1:4, 1:5, 1:6 with the ratio of water to cement set at 1:2 $(\mathrm{W} / \mathrm{C}=0.5)$. All plastic flakes, were of medium size $(\mathrm{M})$. For the initial tests, a small amount of plastic (10\%) replaced the sand to help measure the efficiency of other aggregates more clearly.

Table 5. Material proportion by weight (gm.) in testing for mixing ratio

\begin{tabular}{ccccc}
\hline Block (ID) & Cement & Sand & Water & Plastic flakes \\
\hline R1w05 & 1000 & 900 & 500 & 100 \\
R2w05 & 1000 & 1800 & 500 & 200 \\
R3w05 & 1000 & 2700 & 500 & 300 \\
R4w05 & 1000 & 3600 & 500 & 400 \\
R5w05 & 1000 & 4500 & 500 & 500 \\
R6w05 & 1000 & 5400 & 500 & 600 \\
\hline
\end{tabular}

\subsection{Water-to-cement Ratio}

In the test, the model ratio of cement to sand (without plastic) was used as a reference. The cement to aggregate ratios (sand and plastic) were adjusted from 1:1 to $1: 6$ with a water to cement ratio of 1:1.4 and 1:1 [(W/C) $=0.7$ and 1.0]. The size and quantity of plastic remained the same. This test expanded the scope of the experiment since the variables of the mixing ratios and the amount of water used are related. For example, if the amount of water is increased the bonding of the aggregates will improve without increasing the cement content. This may result in the same compressive strength, but will affect the block's weight and density, which in turn are factors affecting compression performance.

Table 6. Material proportion by weight (gms) in testing water to cement ratio

\begin{tabular}{ccccc}
\hline Block (ID) & Cement & Sand & Water & Plastic flakes \\
\hline R1w07 & 1000 & 900 & 700 & 100 \\
R2w07 & 1000 & 1800 & 700 & 200 \\
R3w07 & 1000 & 2700 & 700 & 300 \\
R4w07 & 1000 & 3600 & 700 & 400 \\
R5w07 & 1000 & 4500 & 700 & 500 \\
R6w07 & 1000 & 5400 & 700 & 600
\end{tabular}




\begin{tabular}{ccccc}
\hline Block (ID) & Cement & Sand & Water & Plastic flakes \\
\hline R1w10 & 1000 & 900 & 1000 & 100 \\
R2w10 & 1000 & 1800 & 1000 & 200 \\
R3w10 & 1000 & 2700 & 1000 & 300 \\
R4w10 & 1000 & 3600 & 1000 & 400 \\
R5w10 & 1000 & 4500 & 1000 & 500 \\
R6w10 & 1000 & 5400 & 1000 & 600 \\
\hline
\end{tabular}

\subsection{Results of Cement to Aggregate Ratio and Cement to Water Ratio Tests}

All the concrete formed from the cement to water ratios 1:1-1:4 produced compressive strengths, which were higher than the regulatory requirement of not less than $2 \mathrm{MPa}$. The blocks that had water to cement ratio (W/C) of 0.5 tended to have better compression strengths than at ratios of 0.7 and 1.0 , especially when the cement to aggregate ratio changed from a 1:4. Exceptionally, at the W/C ratio of 1:5, the block bore a lower level of compression than a block that has a higher ratio of water. This is because water penetrated through the gaps created by the higher volume of plastic flakes, causing lower cracking and peeling of the sample blocks. The blocks obtained from a 1:6 $(\mathrm{W} / \mathrm{C}=1)$ had a more complete shape; however, they bore very little compressive strength, caused by the limited amount of cement binder.

Comparision of the compression force (MPa) $\mathrm{W} / \mathrm{C}=0.5,0.7,1.0$

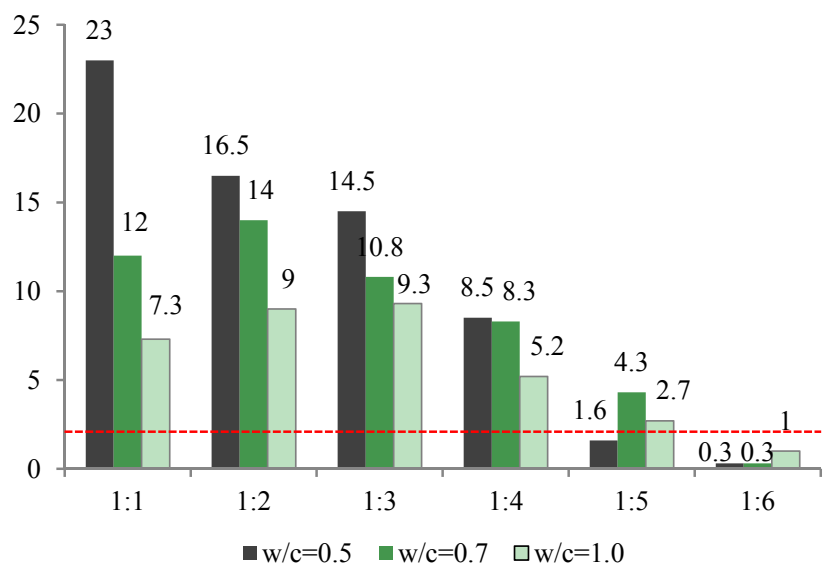

Figure 3. Compressive strength at $\mathrm{W} / \mathrm{C}=0.5,0.7,1.0$

From related studies, it was found that using plastic flakes as an aggregate of concrete blocks would make the block's compressive strength decrease. For example, according to Rahmani et al. (2013), the compressive strength of concrete blocks decreased more than $50 \%$ when plastic flakes replaced sand at $3 \%$. Mazouk et al. (2007) found that when replacing sand with plastic flakes in excess of $10 \%$, the compressive strength of a concrete block will reduce compared to the concrete without plastic flakes. For the test of water to cement ratio, Frigione (2010) found that a reduced amount of water produced a higher compressive strength than using a large amount of water.

In terms of architectural applications, it was found that at the W/C ratio of 1:1-1:4 with water to cement ratio (W/C) of 0.5, 0.7 and 1.0, plastic flakes can be mixed with other aggregates easily. Furthermore, the colour of the flakes are in harmony with the grey concrete. This is because the shades of plastic (white -light grey) will blend in well with the concrete colour (light grey-medium grey) while at the $\mathrm{W} / \mathrm{C}$ ratio of $1: 5(\mathrm{~W} / \mathrm{C}=0.5,0.7)$ the concrete will have more of a sand colour. This (1:5) ratio also caused cracking of the sample block when used. Increasing the water to cement ratio $(\mathrm{W} / \mathrm{C})=1.0$ facilitated the mixing of the aggregates and made the block colour more monochrome than at $\mathrm{W} / \mathrm{C}=0.5,0.7$. However, such a mix creates sedimentation making aggregate amalgamation difficult, in addition to producing a lower compressive strength than at other ratios. As a 
result, the application of this $(\mathrm{W} / \mathrm{C})=1.0$ block gives rise to safety concerns and is therefore unsuitable for building construction.
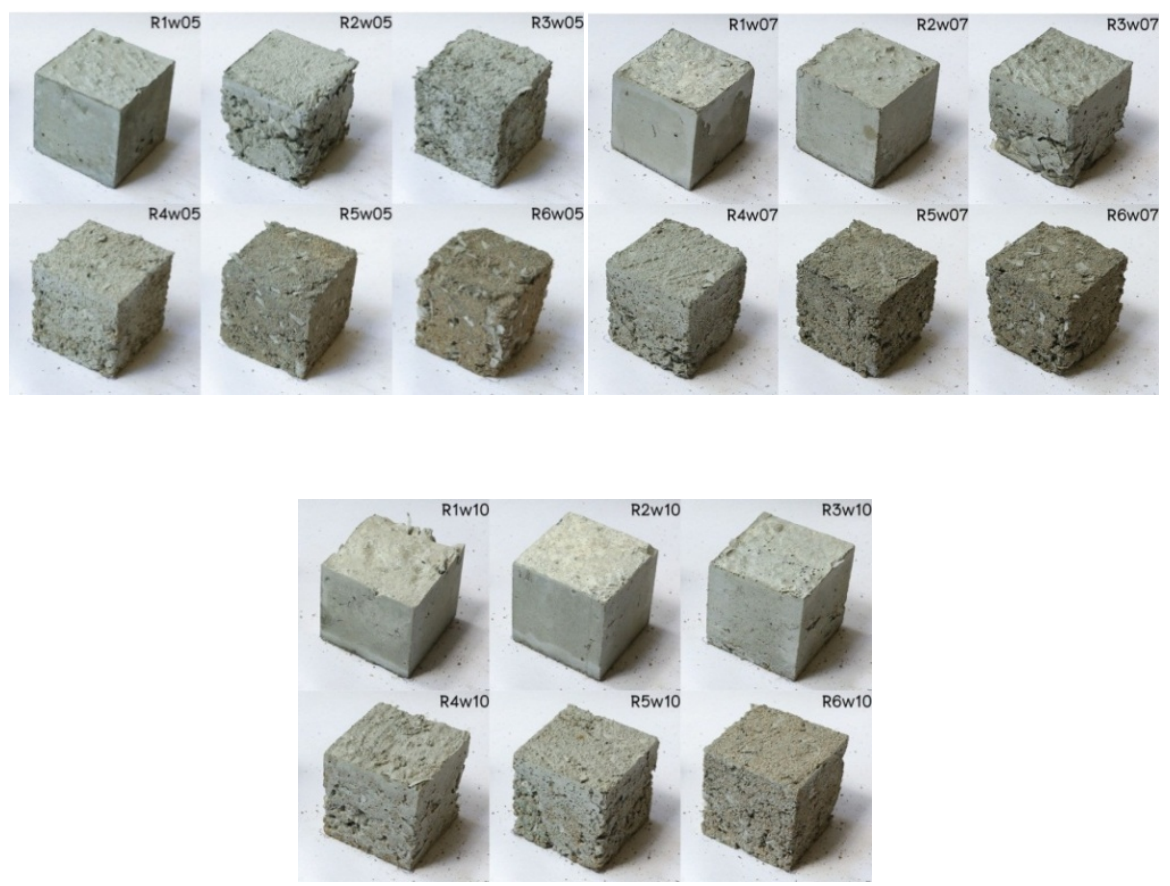

Figure 4. Sample blocks at $\mathrm{W} / \mathrm{C}=0.5,0.7,1.0$

\subsection{Choosing Appropriate Cement to Aggregate (C/A) and Water to Cement (W/C) Ratios}

Regarding the compressive strength test results and architectural guidelines, it was found that 1:4-1:6 (C/A) ratios were likely to be difficult to implement because they had a relatively low compressive strengths, plus the concrete in the casting did not hold together well. At (C/A) ratios of 1:1-1:2, the blocks had a relatively high compressive strength for use in a non-load bearing wall, however they were quite heavy. The appropriate (C/A) ratio for use should be at $1: 3$. The $(\mathrm{W} / \mathrm{C})$ ratio of $1: 2(0.5)$, which provided better compressive strength than other cement-water ratios, was chosen based on the selected (C/A) mixing ratio range of 1:2-1:3. In addition, because of the lower amount of sand than at the (C/A) ratios of 1:4-1:6, the aggregates could still be mixed well.

\subsection{Plastic Flake Size Variability}

Tests were conducted to discover the comparative compression strengths of the concrete blocks by using plastic flakes (large, medium and small (L, M, S) used individually and in various combinations) as a proportion of the aggregate.

Cement, sand, plastic and water were combined as follows:

- The ratio of cement to aggregate (C/A) remained at 1:2 having already being determined as the optimal ratio for strength. This ratio also helped recognize the difference in performance of compressive strengths more clearly than the ratios having more sand, such as 1:5, 1:6 which had a smaller percentage of cement.

- The ratio of cement to water $(\mathrm{C} / \mathrm{W})$ remained at 2:1

- The ratio of sand-aggregate to plastic-aggregate was fixed at 4:1. Using a $20 \%$ proportion demonstrated the efficiency of each size of plastic flakes better than at $10 \%$. 
Table 7. Component proportions by weight (gms)

\begin{tabular}{|c|c|c|c|c|c|c|}
\hline \multirow[t]{2}{*}{ Block ID) } & \multirow[t]{2}{*}{ Cement } & \multirow[t]{2}{*}{ Sand } & \multirow[t]{2}{*}{ Water } & \multicolumn{3}{|c|}{$\begin{array}{l}\text { Plastic } \\
\text { flakes }\end{array}$} \\
\hline & & & & $\mathrm{L}$ & M & $\mathrm{S}$ \\
\hline S0 (Ref) & 1200 & 2400 & 600 & - & - & - \\
\hline S1 & 1200 & 1920 & 600 & 480 & - & - \\
\hline S2 & 1200 & 1920 & 600 & - & 480 & - \\
\hline S3 & 1200 & 1920 & 600 & - & - & 480 \\
\hline S4 & 1200 & 1920 & 600 & 240 & 240 & - \\
\hline S5 & 1200 & 1920 & 600 & - & 240 & 240 \\
\hline S6 & 1200 & 1920 & 600 & 240 & - & 240 \\
\hline S7 & 1200 & 1920 & 600 & 160 & 160 & 160 \\
\hline
\end{tabular}

The test results showed that the cement blocks containing the highest proportion of small plastic flakes had the highest levels of compressive strength. As seen in charts 4.3 block S3 containing only small sized flakes had the highest compressive strength at $24 \mathrm{MPa}$, followed by block $\mathrm{S} 5$ at $20.5 \mathrm{MPa}$, containing a 1:1 mix of small and medium flakes. Although block S6 also contained small flakes, results revealed that when combined with the larger flakes (L.240gm + S.240 gm) the block's MPa was $60 \%$ of S3 levels and 50\% of S5. Similarly, for S4 blocks, when large plastic flakes (L) are combined with medium plastic flakes (M), the blocks bore less compressive strength than blocks S2 (M), which consisted of only medium sized flakes. Blocks utilising only large flakes (S1) had the lowest compressive strengths, at $1.45 \mathrm{MPa}$. Even when combined with small and medium flakes the inclusion of large flakes reduced the compressive strengths of the blocks considerably. A situation which would be amplified if cement to aggregate ratios were 1:3 - 1:5 This signifies that large plastic flakes are an unsuitable aggregate in the forming of concrete blocks.

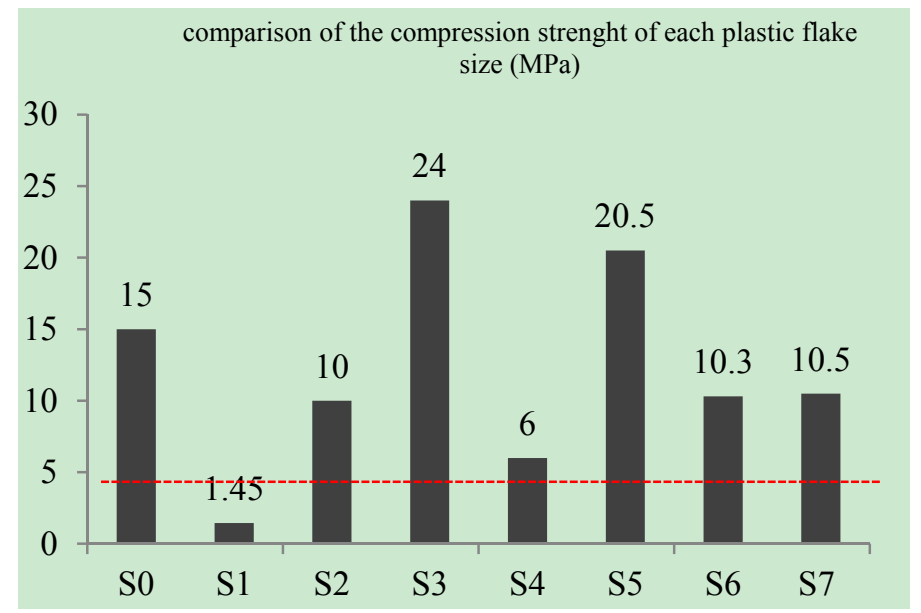

Figure 5. Compressive strength in testing plastic flake size

The use of medium (M) plastic flakes alone, as in S2, produced a compressive strength of $10 \mathrm{MPa}$, an average when compared to the use of large and small plastic flakes. When compared to S5 (blocks mixed with small plastic flakes), S2 blocks could bear less compressive strength than S5 blocks by about 20\%. The C/A in this experiment was set to $1: 2$, where blocks could provide relatively high compressive strength, but could not be used when below the minimum of $2 \mathrm{MPa}$. Therefore, medium flakes are applicable for forming blocks if used at a C/A mixing ratio of 1:3-1:5.

When compared to related studies, results were found to be in accordance with Albano et al. (2009) who compared the size of plastic flakes used. The findings indicated that using small plastic flakes mixed with medium ones would bear similar compressive strength to using small plastic flakes alone. In contrast, using large 
plastic flakes could bear less compressive strength.

For the sample blocks (S1, S4, S7) using large plastic flakes (L) the cement and aggregates had poor adherence and the plastic flakes would tend to converge, making the surface of the sample block uneven or very rough. If they are used to build walls, it can be difficult to set the centre or plane of the wall and may cause the wall to be unevenly warped. However, S2, S3, S5 and S6 blocks using smaller plastic flakes have a smoother surface and can be produced in a cube shape easily. Therefore, blocks with small flakes are more suitable for building application. Because plastic flakes are transparent or white, they are in harmony with the grey colour of the concrete, although colours vary depending on different mixing ratios.

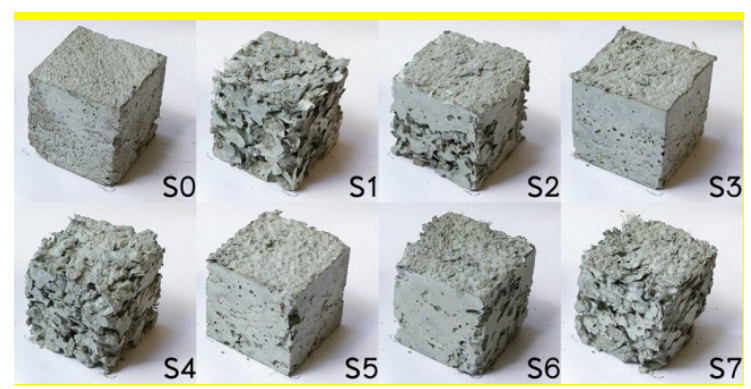

Figure 6. Blocks mixed with different sizes of plastic flakes

\subsection{Guidelines for Selecting and Using Plastic Flakes}

Medium (M) and small (S) plastic flakes should be used for creating cement blocks because they provide better compressive strength than larger plastic flakes (L). If the flakes are used in larger quantities, the block density decreases resulting in lower thermal conductivity. This, however, can be modified by altering the thickness in the concrete 'forming' stage. The plastic flakes from re-cycling plants are mostly size M and L. If small sized (S) plastic flakes, are to be used, they need to be ground, which will increase the cost. Whereas size $\mathrm{M}$ can be used immediately. The remaining size L plastic flakes need to be ground further, which again increases cost.

Table 8. Guidelines for using selected plastic flakes

\begin{tabular}{|c|c|c|c|c|}
\hline & Selected PET & Grinding & Grinding Cost & $\begin{array}{c}\text { Plastic } \\
\text { Obtained }\end{array}$ \\
\hline Guideline1 & $\begin{array}{c}\text { Size } \\
\text { M 50\% }\end{array}$ & - & $\begin{array}{l}50 \% \text { of the } \\
\text { total cost }\end{array}$ & Size M \\
\hline $\begin{array}{c}\text { Plastic } \\
\text { M }\end{array}$ & $\begin{array}{c}\text { Size } \\
\text { L 50\% }\end{array}$ & $\begin{array}{c}\text { Ground to } \\
\mathrm{M}\end{array}$ & & $100 \%$ \\
\hline Guideline2 & $\begin{array}{c}\text { Size } \\
\text { M 50\% }\end{array}$ & - & $\begin{array}{c}50 \% \text { of the } \\
\text { total cost }\end{array}$ & $\begin{array}{c}\text { Size M } \\
50 \%\end{array}$ \\
\hline Plastic & Size & Ground to & & Size \\
\hline $\mathrm{M}+\mathrm{S}$ & L $50 \%$ & S & & S $50 \%$ \\
\hline Guideline 3 & $\begin{array}{c}\text { Size } \\
\text { M 50\% }\end{array}$ & $\begin{array}{c}\text { Ground to } \\
\mathrm{S}\end{array}$ & $\begin{array}{l}100 \% \text { of the } \\
\text { total cost }\end{array}$ & Size S \\
\hline $\begin{array}{c}\text { Plastic } \\
\text { S }\end{array}$ & $\begin{array}{c}\text { Size } \\
\text { L 50\% }\end{array}$ & $\begin{array}{c}\text { Ground to } \\
\mathrm{S}\end{array}$ & & $100 \%$ \\
\hline
\end{tabular}

If the results, from the above table, are considered on their compressive strength and production costs, the second guideline is the most appropriate. This is because S5 $(\mathrm{M}+\mathrm{S})$ can bear less compressive strength than guideline 3 or S3 (S)sample blocks at $14.58 \%$, with $50 \%$ less cost.On the other hand, guideline 1 had the same 
cost as guideline 2, but could bear less compressive ratio than S3 (S) sample blocks at 58.3\%. Therefore, the second guideline using two types of plastic $(\mathrm{M}+\mathrm{S})$ is the most applicable in terms of production cost and performance.

\subsection{Determination of Aggregate Ratio - Sand: Plastic}

After concluding an analysis of the first test, it was found that a cement to sand $=1: 3$ and water to cement $=1: 2$ were the optimal ratios. The ideal size of the plastic flakes was medium (M) and small (S) mixed together in a 1:1 ratio, replacing aggregate with plastic flakes at $0-20 \%$ (added $5 \%$ at a time). Finally the blocks were analysed for physical properties, and compressive strength.

Table 9. Material proportion by weight $(\mathrm{g})$ in testing plastic flake proportion testing

\begin{tabular}{cccccc}
\hline & & & & \multicolumn{2}{c}{ Plastic flakes } \\
\cline { 3 - 5 } Block (ID) & Cement & Sand & Water & $\mathrm{M}$ & $\mathrm{S}$ \\
\hline P3-00(Ref) & 1000 & 3000 & 500 & - & - \\
P3-05 & 1000 & 2850 & 500 & 75 & 75 \\
P3-10 & 1000 & 2700 & 500 & 150 & 150 \\
P3-15 & 1000 & 2550 & 500 & 225 & 225 \\
P3-20 & 1000 & 2400 & 500 & 300 & 300 \\
\hline
\end{tabular}

The compressive strength of sample blocks with 5 and 10\% replacement ratios (P3-05, P3-10) was significantly higher than that of the reference blocks. The maximum compressive strength at $10 \%$ replacement was $14.4 \mathrm{MPa}$ which was higher than the minimum compressive strength set at $2 \mathrm{MPa}$, but the compressive strength was significantly reduced at the replacement levels of 15 and $20 \%$ (P3-15, P3-20) when the values were approximately 2.2-2.4 $\mathrm{MPa}$. The two blocks were relatively close to the minimum compressive strength. Therefore, using the sample blocks containing $15 \%$ or more plastic flakes should be used carefully and safety factors should be taken into account. The mixing ratio may be adjusted throughout the tests, such as increasing cement content and reducing the water to cement ratio.

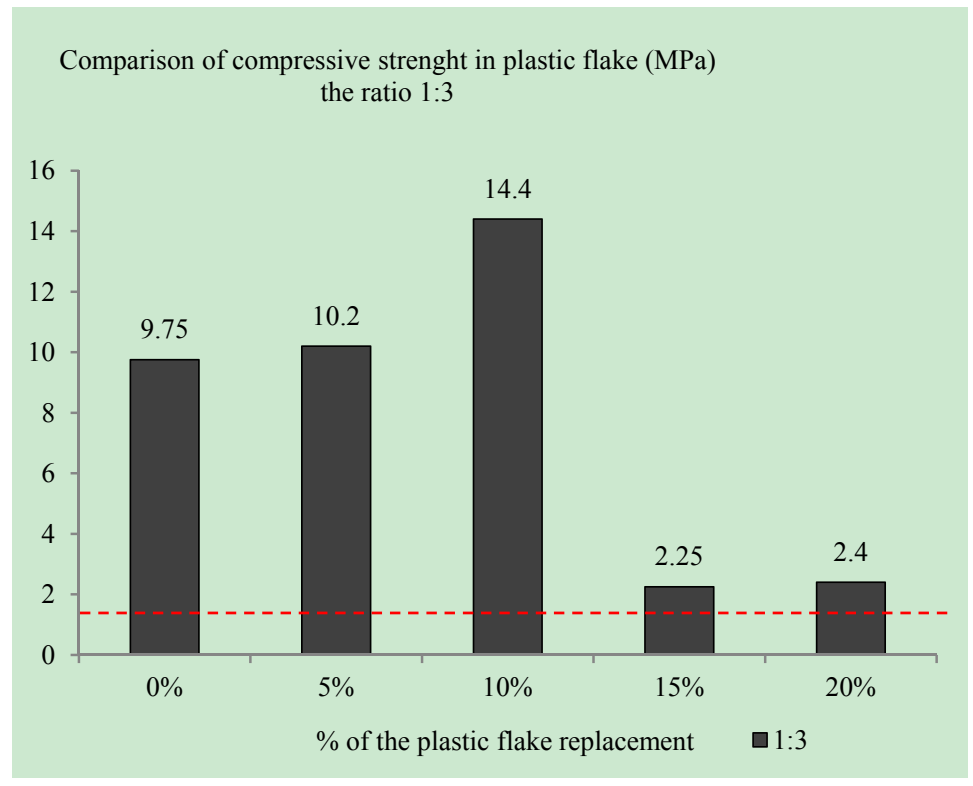

Figure 7. Compressive strength in testing plastic flake replacement

Overall, compressive strength testing is consistent with other relevant research. In replacing sand with the plastic flakes by no more than $5-10 \%$, the blocks will only have a slightly lower compressive strength or, in some cases, have greater compressive strength, as stated by Mazouk et al. (2007). At the sand replacement ratio of $15 \%$ and 
above, the compression is reduced significantly. As the number of plastic flakes, which have an overall size larger than sand, increases it produces the possibility of gaps and holes inside the blocks. This can reduce the adhesion between the concrete and the plastic. As a result, the sample blocks have a lower compressive strength, and are easy to break (Mazouk et al., 2007; Shalaby et al., 2013; Rahmani et al., 2013).

Casting, mixing and removing of concrete forming boards could be done easily, and the surface was relatively smooth. However, for blocks with a plastic flake ratio of $10 \%$ or more, the surface was rather rough, and the sand on the surface fell off slightly. There was a greater cracking of the plastic flakes compared to the sample blocks P3-00, P3-05, especially at the sand replacement ratio of 15 and 20\% (P3-15, P3-20). Overall, the sample blocks obtained were still in a complete cube shape as shown in Figure 4.4 (S3, S5). The colour on the surface of the blocks was a combination of concrete-grey and orange sand. The blocks, which had a high proportion of plastic flakes at 15 and $20 \%$, were a lighter grey, and the white colour of the plastic flakes could easily be noticed. Overall, the sample blocks, which aligned quite well, could be used in non-load-bearing walls. Render or plaster provided a smooth, flat surface.

\section{Conclusions and Recommendations}

This paper presents the effects on the density and compressive strength of concrete blocks when fine aggregate is replaced by plastic bottle flakes. The fine sand aggregate was replaced in the mortar mix at varying percentage points and the data, on density and compressive strength, was recorded. The study results indicate that the concrete blocks, with plastic flake replacing sand in the mortar mix at a ratio of $20 \%$ by weight, can be used in the construction of a non-load-bearing wall. Many of the blocks in the study, however, had a compressive strength only slightly higher than the minimum standard value (2 $\mathrm{MPa})$. This suggests that the blocks composition needs to be improved in order to bear greater compression. From the result of this study, the following conclusions and recommendations can be applied to maintain the quality of the products.

1) It is recommended to increase the cement to aggregate ratio from 1:3 to1.2:3 or higher.

2) It is recommended to reduce the water to cement ratio (W/C) to $0.4 \%(1: 2.5)$ or lower.

3) In the concrete blocks having a high standard of compressive strength such as Block ID P3-10 (14.4 $\mathrm{MPa}$ ) or other high compressive strengths, the replacement of sand by plastic flake aggregate could be as high as $25-30 \%$ or higher. These concrete blocks can still be utilised because the compressive strength would be in excess of the standard of $2 \mathrm{MPa}$.

Based on the experiments in the study, the use of PET in concrete blocks has the potential to limit the amount of plastic being disposed of into the environment. Nowadays, PET is a good quality product and biodegrades extremely slowly, having a serious negative impact on the environment. Systematic use of the smaller sized PET aggregate in the construction industry could be a good solution to reducing this environmental impact. Hence the necessity of further study needs to focus on the development of these three guidelines to minimise production costs of concrete blocks containing PET.

\section{References}

Akçaözoğlu, S., Kubilay A., \& Cengiz, D. A. (2013). Thermal Conductivity, Compressive Strength and Ultrasonic Wave Velocity of Cementitious Composite Containing Waste PET Lightweight Aggregate (WPLA). Composites Part B 45(1), 721-726. https://doi.org/10.1016/j.compositesb.2012.09.012

Albano, C. N., Camacho, M., Hernández, A. M., \& Gutiérrez, A. (2009). Influence of Content and Particle Size of Waste Pet Bottles on Concrete Behavior at Different W/C Ratios. Waste Management, 29(10), 2707-2716. https://doi.org/10.1016/j.wasman.2009.05.007

Asdrubali, F., Francesco, D., \& Samuele, S. (2015). A Review of Unconventional Sustainable Building Insulation Materials. Sustainable Materials and Technologies, 4(2), 1-17. https://doi.org/10.1016/j.susmat.2015.05.002

Cox, P. M., Betts, R. A., Jones, C. D., Spall, S. A., \& Totterdell, I. J. (2000). Acceleration of Global Warming Due to Carbon-Cycle Feedbacks in a Coupled Climate Model. Nature, 408(6809), 184-187. https://doi.org/10.1038/35041539

Frigione, M. (2010). Recycling of PET Bottles As Fine Aggregate in Concrete. Waste Management, 30(6), 1101-1106. https://doi.org/10.1016/j.wasman.2010.01.030

Ismail, Z. Z., \& AL-Hashmi, E. A. (2008). Reuse of Waste Iron As a Partial Replacement of Sand in Concrete. Waste Management, 28(11), 2048-2053. https://doi.org/10.1016/j.wasman.2007.07.009 
Jambeck, J. R., Roland, G., Chris, W., Theodore, R., Siegler, M. P., Anthony, A., ... Kara, L. L. (2015). Plastic Waste Inputs from Land into the Ocean. Science, 347(6223). https://doi.org/10.1126/science.1260352

Joshua, O., \& Lawal, P. O. (2011). Cost Optimization of Sandcrete Blocks through Partial Replacement of Sand with Lateritic Soil. Epistemics in Science, Engineering and Technology, 1(2), 89-94.

Marzouk, O. Y., Dheilly, R. M., \& Queneudec, M. (2007). Valorization of Post-Consumer Waste Plastic in Cementitious Concrete Composites. Waste Management, 27(2), 310-318. https://doi.org/10.1016/j.wasman.2006.03.012

Oyekan, G. L., \& Kamiyo, O. M. (2011). A Study on the Engineering Properties of Sandcrete Blocks Produced with Rice Husk Ash Blend Cement. Journal of Engineering and Technology Research, 3(3), 88-98.

Rahman, M., Mah, M., \& Chowdhury, T. (2013). Utilization of Waste PET bottles as aggregate in masonry mortar. International Journal of Engineering Research \& Technology, 2(11), 1300-1305.

Rahmani, E., Dehestani, M., Beygi, M. H. A., Allahyari, H., \& Nikbin, I. M. (2013). On the Mechanical Properties of Concrete Containing Waste PET Particles. Construction and Building Materials, 47, 1302-1308. https://doi.org/10.1016/j.conbuildmat.2013.06.041

Rochman, C. M., Anna-Marie, C., \& Albert, A. K. (2016). Plastic Debris and Policy: Using Current Scientific Understanding to Invoke Positive Change. Environmental Toxicology and Chemistry, 35(7), 1617-1626. https://doi.org/10.1002/etc.3408

Shalaby, A., Ward, A., Refaee, A., Abd-El-Messieh, S., Abd-El-Nour, K., \& El-Nashar, D. (2013). Compressive Strength and Electrical Properties of Cement Paste Utilizing Waste Polyethylene Terephthalate Bottles. Journal of Applied Sciences Research, 9(7), 4160-4173.

TIS 1505-2541. Autoclaved Aerated Lightweight Concrete Elements. Thai Industrial Standard, 1998.

TIS 408-2525. Standard Test Method for Compressive Strength of Concrete Specimens. Thai Industrial Standard, 1982.

TIS 58-2533. Standard for Hollow Non-Load-Bearing Concrete Masonry Units. Thai Industrial Standard, 1990.

TIS 77-2517. Brick Wall. Thai Industrial Standard, 1974.

\section{Copyrights}

Copyright for this article is retained by the author(s), with first publication rights granted to the journal.

This is an open-access article distributed under the terms and conditions of the Creative Commons Attribution license (http://creativecommons.org/licenses/by/4.0/). 